\title{
Synchronizing the city with human-based spaces
}

\author{
János Gyergyák \\ University of Pécs \\ Faculty of Engineering and Information Technology, Department of Architecture and Urban Planning \\ e-mail: gyergyak.janos@pmmik.pte.hu
}

\begin{abstract}
The paper is about to summarize the most important development tools to make the urban spaces more human friendly in Denver, Colorado. There are more needs for having more livable and sustainable areas by reducing the use of automobiles and focusing on multimodal street design. The strategies are the basic elements to make our urban spaces better and happier from The United States to Hungary
\end{abstract}

Key words: America, new direction, urban design, public spaces, street life, communities, happiness

\section{Introduction}

Since the $20^{\text {th }}$ century the United States of America has been home to numerous forms of urban planning, which have not had the platform to be rationalized in the consolidated European city structure. The pattern of American cities was imported from Europe, and these new spaces functioned as an experimental laboratory of the European visions in urban planning. After importing the grid and "axial" urban plan (baroque architectural characteristics), the thoughts of urban planning (forms and elements) managed to spread freely due to the close cultural and economic relationship between Europe and the "New World". In the $21^{\text {st }}$ century the American grid plan, then skyscrapers began to take hold, which had become the symbol of the American cities by that time. The process, namely the transportation of urban planning elements got strengthened only after this. The European modernists imported a new style first, then their intellectual capital during the time when they were escaping from the Second World War. In the 1960s the American suburbs and highways also contributed to this process. During the continuous exchange of knowledge these characteristics of dual nature were constantly perceivable. On one side, the United States of America was the symbol of novelty, while on the other side Europe was regarded as the manifestation of traditions and past.

Denver is the capital of Colorado, the fifth happiest state in the United State [1]. Besides the good ranking of the state, the city also performed successfully; the Denver-Aurora-Lakewood 
combined statistical area gained three places to rank 13th on the list of 2016 Best-Performing Cities [2], based on created and sustained jobs. These two results show that economy and urban comfort can be connected, and obviously, having or not having a job can have a significant impact on personal happiness, but the quality of life is important either.

If we go back in the history of American cities, we can see only the good working cities with factors of urban comfort, but not the same types as now. The intervention of the automobile, the promise of the future, the suburban detached and semi-detached houses, the urban sprawl phenomenon, created a totally new life in the sixties. Moving out from the cities outward helped middle-class families to improve the quality of their lives. Fresh air, space and access to nature were the most important benefits of these new places. But now we see that people, who are living farther from urban areas, spend more and more time and money with commuting. In the late 1960s the average American family spent one-tenth of the family budget on traveling (commuting), now one in five dollars is spent on the same purpose [3].

Worshipping the twin gods of Smooth Traffic and Ample Parking [4] initiated some changes. Some cities like Portland and Denver (besides so many other places) are working to alter the traditional urban design and start new strategies.

\section{Importance of good urban design}

"Sixty-four percent of the college-educated millennials choose first where they want to live, and then they look for a job" [5]. This statement shows the importance of qualities related to settlements. The most important challenge of cities is to keep and attract the well-educated population, mostly the members of the new generation, the Millennials.

Cities today, but rather in the future, will have to accommodate the wishes of the users to provide them with a useful, healthy and sustainable environment. Some researchers say that capitalism in the future will be about the free market of people, which means that the world of labor will be considerably freer than any time before and will be available only in that surrounding where they feel happy.

The future of cities is not only about automobiles, but transportation. Happy life is not connected to the isolated automobiles and traffic jams, but rather well-designed urban areas with "complex streets" or "multimodal street" design. According to Cristopher Alexander, the harmony of people depends on their harmony with the surroundings [6]. Unfortunately, there is an important contradiction in some of the cities; many people are moving to urban areas for having better jobs and a better quality of life, but the most dynamic economies of the twentieth century produced the most miserable cities all [7].

Thanks to the revolution of media, and the new platforms of social media, humans started to break away the real human connections. Unfortunately, the old fashioned urban design helped to pave the way of this process as well; the longer commuter times, the money-based developments, the lack of safe pedestrian and cycling areas and the missing public transportation are factors of ruining our social connections. But social connections are vastly important; according to Charles Montgomery, the Canadian writer and urbanist, happiness, or 
urban comfort is based on social connections [8]. But how do we have to change our built environment for having more of them?

\section{Strategies of Denver toward a happier city life}

Building a sustainable Denver depends on a common understanding that people, nature, the built environment, the economy and the social structure all depend on each other. A sustainable city is a place where most citizens, in most of the cases, unite in the common understanding that people and things depend on each other. That "uniting" in "common" to sustain their city is the meaning of "community" [9].

Two city-wide plans, the Comprehensive Plan 2000 and Blueprint Denver are responsible for creating a "happier" surrounding for Denver. The frame of the first one is a whole city, which focuses on establishing long-term strategies to ensure that Denver is and will be a livable place for its people, meanwhile Blueprint Denver is a supplement to Comprehensive Plan 2000 , with the same scope but analyzing only the land use and transportation, as the key factors of the sustainable and livable strategy, which are the basic steps for having happiness.

As complementing and enhancing the two aforementioned city-wide plans, two initiatives began as Denver Living Streets Initiative and Transit-Oriented Development Strategic Plan.

The Denver Living Streets Initiative started in 2007. The study is dealing with improving the city life focusing on that $1 / 3$ of the Americans who do not drive cars [10] and what is shocking, $70 \%$ of the measured trips occur within 3 miles of the household [11]. But many times, there are not any other options for the Americans, mostly in the suburbs for people to go dealing with their daily business, because of the lack or maybe the existing but unsafe, sidewalks. The plan is to deal with the development of the current street network to transform it into "complex streets" or "multimodal streets", which are safe, comfortable and convenient for all pedestrians and cyclists, who use public transportation besides the automobiles. Beyond safe public spaces, the plan is to emphasize a lot of other advantages as community and (local) economic development, public health as the good aspects of redesigning the streets in Denver (or anywhere).

Thanks to the topic, the condition of the street is continuously evaluated by the locals with using the WALKscope mobile tool, developed by WalkDenver and PlaceMatters. The platform has been collecting data, related to sidewalks, intersections, and pedestrians in the Denver metro area. Fig. 1. These pieces of information will help create an inventory of pedestrian infrastructure, identify gaps, and build the case for improvements [12]. 


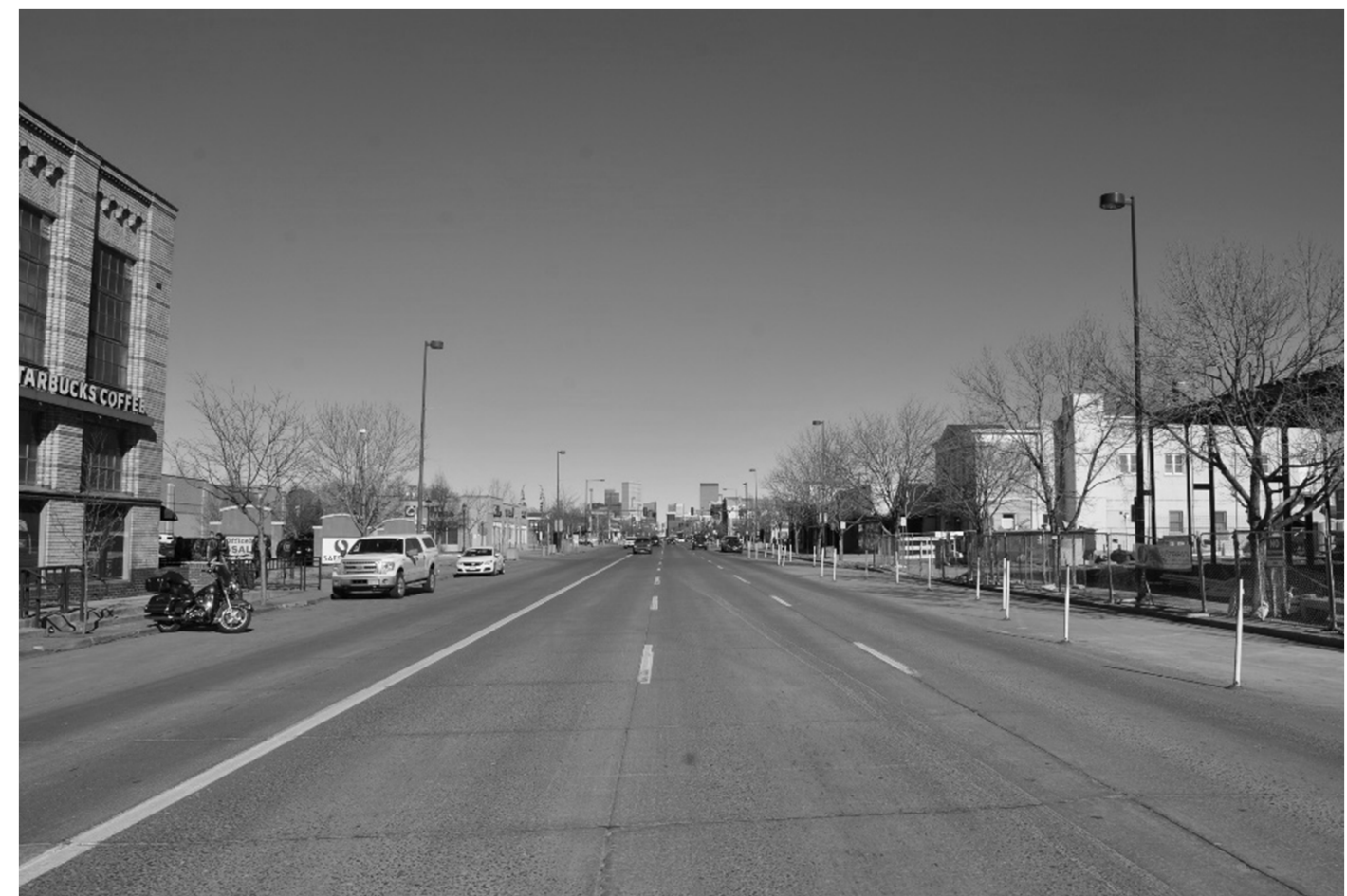

Figure 1: Section from the S. Broadway, Denver, which received the score "2" points (maximum 5) on http://www.walkscope.org/

The other key plan is the Transit-Oriented Development Strategic Plan. The TOD (full name: Transit-Oriented Development or Transit-Oriented Denver) is a development program around light-rail stations to connect people between urban and suburban areas in order everyone can be part of the city-wide community. Denver is taking a system-wide approach to implement not just transit oriented developments (TOD), but also transit communities for all of the citizens in Denver [13]. The plan offers development areas at the stations along the existing and the new light rail system for public and private money. The plan distinguishes five different typologies from each other based on the location (downtown, urban center, general urban, urban, suburban) with functional overlays, and the missing elements of the existing city life. The plans and the connected action plans are made for establishing sub-centers along light rail stations, with local walkable areas of mixed use, creating local communities. The areas can accommodate affordable housing projects as well, to offer public transportation for low income families instead of using automobiles.

Besides the city-wide plans the small area plan is the scale, which is about the exact details of the program with the execution process. Actually this is the scale where the human-based space arrangement is planned. Small area plans have been made in three different geographic scales like neighborhood, corridor, and district, depending on the cohesive set of characteristics. In this category the detailed elements of the TOD are found like "Station area plans", and the other type is the "Neighborhood plans". These plans focus on engaging residents and businesses in identifying a future vision for the area and provide strategies and recommendations for achieving that vision, land use and future development to help ensure neighborhoods to grow as envisioned by the plan. One of the most important advantages of 
the detailed planning is that the studies and plans provide analysis, details, and guidance for local areas that city-wide plans cannot.

The station plans consist of the key components of the planning process to provide strategies on how to realize the general city vision at some exact locations. The plans are dealing with urban design, land use, mobility, infrastructure, economic opportunities and the community of a bounded area supplemented with an important issue; the way how all of these can be implemented in synergy. This complex way of planning is the key factor of success, where private and public investments can work together for reaching the common goals of the city through developing local communities.

The other small area planning process is the Denver's Neighborhood Planning Initiative.

This new type of plan is a long-term commitment to ensure that every area of the city can enjoy the benefits of an area plan. Over the next decade, residents, neighborhood groups, and community leaders will work in tandem with the city's neighborhood planning team to create a vision and plan for their specific area [14].

But all of these efforts are not enough, if the city does not do its best to develop its central area, the downtown. The main street of Denver, 16th Street Mall is the only pedestrian friendly area of the metro area (working like a shopping street). The area formerly used by automobiles transformed into the main public space of the city in 1982. In 2016, after more than two decades and many studies, the city ordered its new development plan called Dowtown Denver 16th st Mall- Small Steps Towards Big Change, made by the studio of Jan Gehl, one of the most prominent people and design companies of the human-based city development. This report outlines the first steps of an action-oriented planning approach with the goal of turning 16th Street into a true destination for the people from every neighborhood in the city [15].

The building of key importance in the urban strategy is the Union Station, which used to be considered as the central railway station of the city until the regional transport company bought the building with the surrounding industrial area in 2001, thus making it the main project of the downtown LoDo (Low Downtown). Fig.2. The former railway station lives on as a transport and cultural intermodal center unifying the train, tram and bus lines with some urban cycling facilities, while the dozens of city services have formed this building into a real city space. Several restaurants, bars and confectioneries have been opened in its internal spaces on the ground floor, while on the two top floors the Crawford hotel welcomes its guests with 112 luxury rooms. However, it has only been a little proportion of the developments. Condominiums including hundreds of flats and commercial facilities have been initiated to build from private and public financial funds, hence giving sense to the formerly neglected industrial area in the heart of the city. By means of its multiple functions and pedestrian-friendly intermodal street structure, it has become the symbolic element of Denver, the youth and the livable downtown, where the real estate market, offices and services are available in high quality and quantity. 


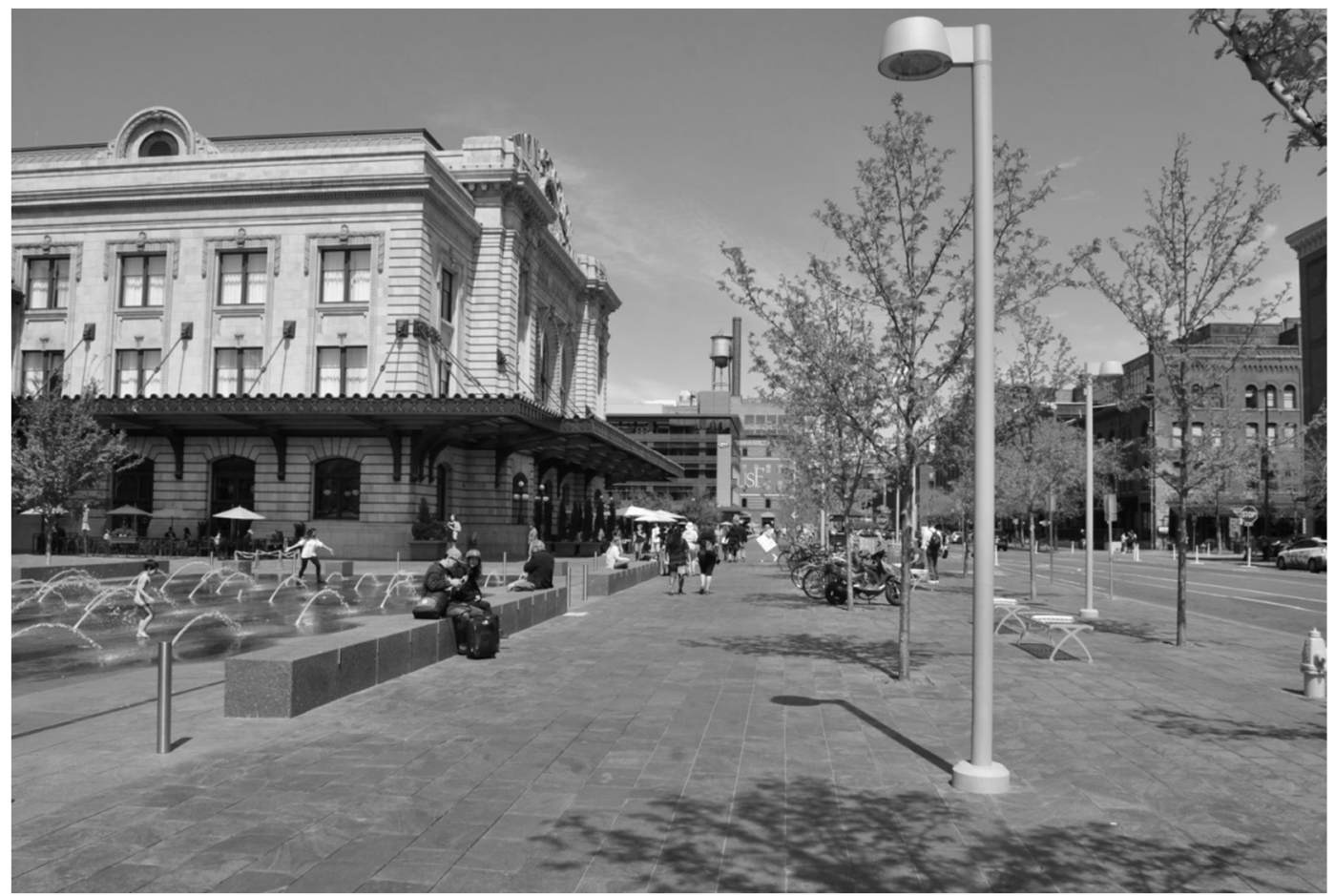

Figure 2: Denver, Union Station with its vibrant urban life, functioning as the engine of the new public life downtown

\section{Comparison of these strategies with European country, Hungary}

The mentioned new types of city plans are missing from the general tools of city development in some European cities. Many times we say that the European cities have been established, which is true, but the design always has to change according to the new life style and innovations in cities. These places have to follow the latest trends and prepare for working as an adaptive and resilient structure.

Hungarian cities mostly focus on the use of land, as a basic regulation, meanwhile the transportation of these areas remains in the background. Strategies like city development plans, and integrated strategies for city development are dealing with a social and economic context, as well, but do not concentrate on transportation, or details like masterplans and exact action plans. Public spaces are determined by the walls of buildings, however, surfaces and functions are neglected in most of the cases. Public spaces, as the lands of everybody, or sometimes "nobody", suffer from the lack of our attention. The design of streets, squares and parks are not among the primary focuses, and therefore they have started losing their communities. 
Pécs, the previous European Capital of Culture, is a good example for comparison. Fig. 3. The fifth biggest Hungarian city has city-wide plans like a city concept plan, focusing on general development till 2030, integrated city development strategy, focusing on social and economic elements, and city regulation plans dealing with mostly land use. However, unfortunately, the city, or the Hungarian system has not come up with a plan which is looking for better traffic solutions, or more attractive public life.

Quite often, there are grassroots initiatives aiming to the development of a public space like the public garden, or providing public functions for abandoned buildings, but these cannot result in distinctive and broad effects. The lack of small-area plans, the elements which are about placing the main principles onto a human scale, cannot be found in the Hungarian system, thus claiming that the public life of the Hungarian cities are less important than land use and traffic networks.

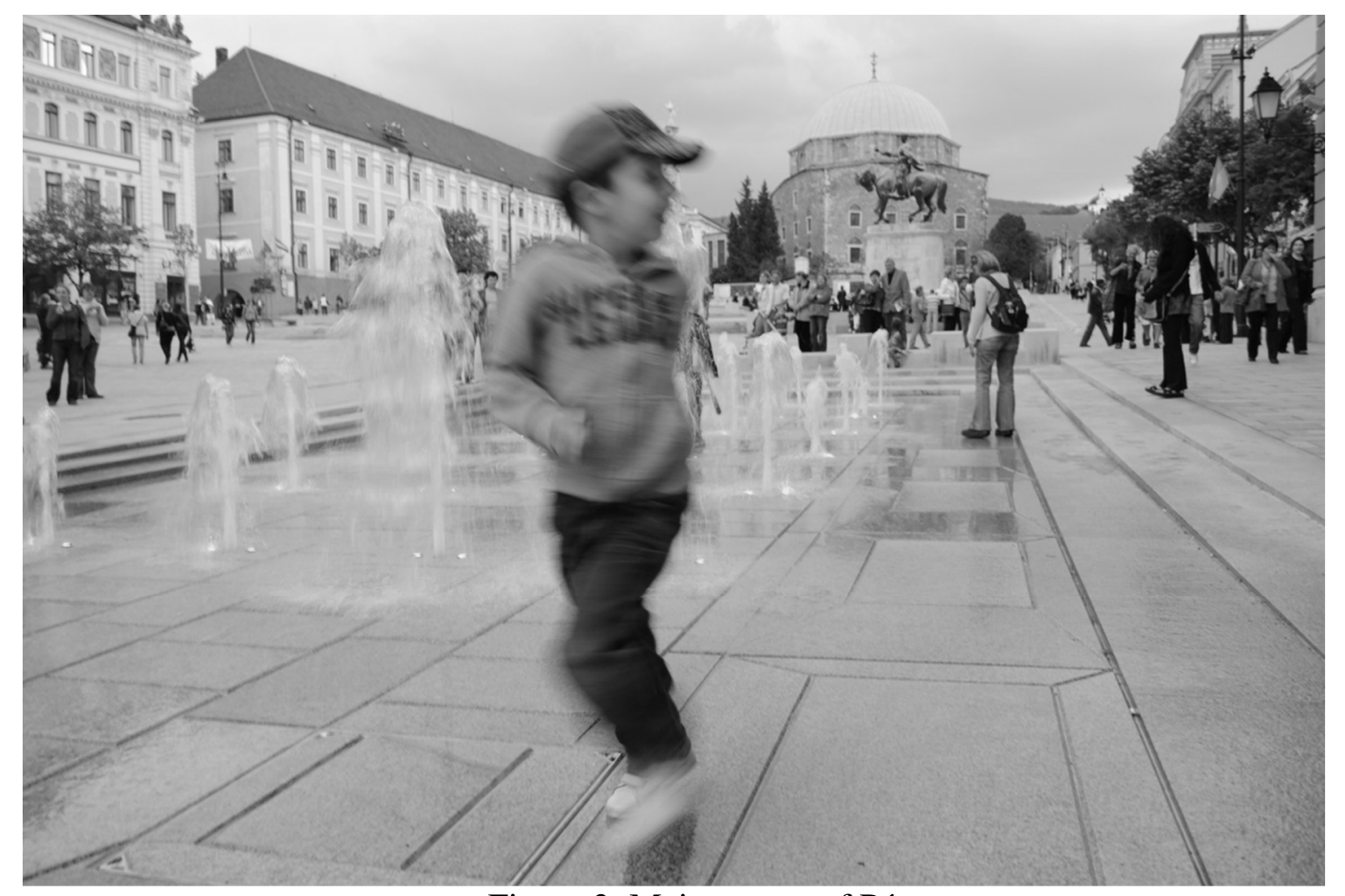

Figure 3: Main square of Pécs

The city could improve their public space network, thanks to the European Capital of Culture title, but this was a simple occasion. Since then, the quality of public spaces has been neglected due to the lack of strategy and planning.

\section{Conclusion}

The stake is so high; not just because of the fewer sustainable environments, or the fewer social connections, but lack of using streets and spending more time in cars can threaten us, so that the children of today are going to be those who have a shorter average life expectancy than their parents, because of their problems with obesity [16]. 
The cities have to focus on both city-wide and small area plans at the same time in order to control human based implementations much more [17]. Through a new kind of approach, the common work and design with the developers and citizens can create community based developments, resulting livable and adorable spaces for us and future generations [18].

\section{References}

[1] http://247wallst.com/special-report/2017/02/01/happiest-and-most-miserable-states/

[2] http://www.best-cities.org/2016/best-performing-cities-report-2016.pdf

[3] Lutz, C. Fernandez, A. L. (2010). Carjacked: The Culture of the Automobile and Its Effect on Our Lives. St. Martin's Press

[4] Speck, J. (2012) Walkable City. New York: North Point Press

[5] Patrick C. Doherty and Cristopher B. Leinberger. „The Next Real Estate Boom”. In Speck, J. (2012). Walkable City. New York: North Point Press.

[6] Alexander, C. (1979). The Timeless Way of Buildings. Center for Enviromental Structure Series

[7] Penalosa In Montgomery, C. (2013). Happy City - Transforming Our Lives Through Urban Design. New York: Farrar, Straus and Giroux

[8] Montgomery, C. Happy City - Transforming Our Lives Through Urban Design. Farrar, Straus and Giroux, New York, 2013

[9] Denver Comprehensie Plan 2000, p. 5

[10] Denver Living Streets Overview. p.3

[11] Denver Living Streets Overview. p.6

[12] http://www.walkscope.org/

[13] Denver Transit-Oriented Development Strategic Plan

[14] https://www.denvergov.org/content/denvergov/en/community-planning-anddevelopment/planning-and-design/Neighborhood_Planning_Initiative.html

[15] https://Www.denvergov.org/content/dam/denvergov/Portals/646/documents/planning/P1 ans/16th\%20Street/16th-st-gehl-report-02-2016-web.pdf

[16] Preventing Childhood Obesity: Health in the Balance (Institute of Medicine 2005)

[17] Tkáč, Š., Vranayová, Z. (2013). The "Efficiency electric power grid circles" an ideal micro-urban development approach. Applied Mechanics and Materials. Volume 361363, p. 107-110.

[18] Tkáč, Š., Vranayová, Z. (2015). The Power of Micro Urban Structure, Theory of EEPGC - the Micro Urban Energy Distribution Model as a Planning Tool for Sustainable City Development. SSP - Journal of Civil Engineering. Volume 10(2), p. 29-38. 